\title{
The effects of branched-chain amino acid interactions on growth performance, blood metabolites, enzyme kinetics and transcriptomics in weaned pigs
}

\author{
Markus Karl Wiltafsky ${ }^{1}$, Michael Walter Pfaffl ${ }^{2}$ and Franz Xaver Roth ${ }^{1 *}$ \\ ${ }^{1}$ Department für Tierwissenschaften, Lehrstuhl für Tierernährung, Technische Universität München, Hochfeldweg 6, Freising \\ D-85350, Germany \\ ${ }^{2}$ Department für Tierwissenschaften, Lehrstuhl für Physiologie, Technische Universität München, Weihenstephaner Berg 3, \\ Freising D-85354, Germany
}

(Received 18 February 2009 - Revised 29 July 2009 - Accepted 1 September 2009 - First published online 3 March 2010)

The impact of excess dietary leucine (Leu) was studied in two growth assays with pigs $(8-25 \mathrm{~kg})$. In each trial, forty-eight pigs were allotted to one of six dietary groups. The dietary Leu supply increased from treatment L100 to L200 (three increments). To guarantee that interactions between the branched-chain amino acids (BCAA) were not cushioned either surpluses of isoleucine (Ile, expt 1) or valine (Val; expt 2) were avoided. In the fifth treatment, the effects of a simultaneous excess of Leu and Val (expt 1), or of Leu and Ile (expt 2) were investigated. The sixth treatment was a positive control. An increase in dietary Leu decreased growth performance, and increased plasma Leu and serum $\alpha$-keto-isocaproate levels in a linear, dose-dependent manner. Levels of plasma Ile and Val, and of serum $\alpha$-keto- $\beta$-methylvalerate and $\alpha$-keto-isovalerate, indicated increased catabolism. Linear increases in the activity of basal branched-chain $\alpha$-keto acid dehydrogenase in the liver confirmed these findings. No major alterations occurred in the mRNA of branched-chain amino acid catabolism genes. In liver tissue from expt 2, however, the mRNA levels of growth hormone receptor, insulin-like growth factor acid labile subunit and insulin-like growth factor 1 decreased significantly with increasing dietary Leu. In conclusion, excess dietary Leu increased the catabolism of BCAA mainly through posttranscriptional mechanisms. The impact of excess Leu on the growth hormone-insulin-like growth factor-1 axis requires further investigation.

Leucine excess: Amino acid interactions: Branched-chain $\alpha$-keto acid dehydrogenase: Pigs

Interactions among the branched-chain amino acids (BCAA), such as the performance depressing effects of excess dietary leucine (Leu), are known in several species ${ }^{(1)}$. The impact of high dietary Leu levels needs to be elucidated in order to make correct estimates of adequate supplies and requirements for isoleucine (Ile) and valine (Val). Interactions among the BCAA include their catabolism, because all three compete for the same enzymes that catalyse the first two catabolic steps. The first step is a reversible transamination catalysed by the branched-chain amino acid transaminase (BCAT) isoenzymes, yielding branched-chain $\alpha$-keto-acids (BCKA) that, in the second step, are oxidatively decarboxylated by a mitochondrial, multienzyme branchedchain $\alpha$-keto acid dehydrogenase (BCKDH) complex. This step is irreversible, highly regulated and rate limiting for BCAA catabolism. The BCKDH complex consists of three catalytic components. The E1 subunit, a heterotetramer of $\alpha$ and $\beta$ subunits, is a branched-chain $\alpha$-keto acid decarboxylase. The E2 subunit is a dihydrolipoamide acyltransferase and the E3 subunit is a dihydrolipoamide dehydrogenase ${ }^{(2)}$. In contrast to the other subunits, the E3 is not BCKDHspecific and its expression is not analysed in the present work. BCKDH complex activity is regulated by covalent modification. Phosphorylation of its E1 $\alpha$ subunits by a specific BCKDH kinase (BDKDK) causes inactivation, and dephosphorylation by a specific phosphatase causes reactivation $^{(3,4)}$. The abundance of the bound kinase corresponds to kinase activity ${ }^{(5)}$. This regulation is unusual among amino acid-degrading enzymes, but is similar to the regulation of pyruvate dehydrogenase complex ${ }^{(6)}$. Thus, high dietary Leu levels might increase the catabolism of all BCAA and the nutritional need for Ile and Val. Additionally, there is some evidence that the growth-depressive effects of amino acid deficiencies might be caused in part by impaired action of growth hormone-insulin-like growth factor-1 $(\mathrm{GH}-\mathrm{IGF}-1)$ axis $^{(7)}$. If excess Leu increases Ile and Val catabolism, these amino acids might become deficient and alter GH-IGF-1 expression.

\footnotetext{
Abbreviations: BCAA, branched-chain amino acids; BCAT, branched-chain amino acid transferase; BCATm, mitochondrial BCAT; BCKA, branched-chain $\alpha$-ketoacids; BCKDH, branched-chain $\alpha$-keto acid dehydrogenase; BCKDK, BCKDH kinase; GH, growth hormone; GHR, GH receptor; 4-HPPD, 4-hydroxyphenylpyruvate dioxygenase; IGFALS, insulin-like growth factor acid labile subunit; IGF-1, insulin-like growth factor 1; Ile, isoleucine; KIC, $\alpha$-ketoisocaproate; KIV, $\alpha$-keto-isovalerate; KMV, $\alpha$-keto $\beta$-methylvalerate; Leu, leucine; PC, positive control; SID, standardised ileal digestible; Val, valine.

* Corresponding author: Professor Franz Xaver Roth, fax +498161 715367, email roth_fx@wzw.tum.de
} 
Most experiments on excess dietary Leu in pigs have concentrated on performance parameters ${ }^{(8-10)}$, so data on metabolites, BCAA catabolism and gene expression are sparse or absent. For correct diet estimates, and to guarantee sufficient supplies of Ile and Val, data on the effects of excess dietary Leu on nutritive status are needed for weaned pigs. The aim of the present work was to determine whether excess dietary Leu affects performance, plasma amino acids, serum BCKA, activity of the BCKDH complex, mRNA levels of enzymes involved in BCAA catabolism and mRNA levels of genes related to $\mathrm{GH}-\mathrm{IGF}-1$.

\section{Materials and methods}

\section{Animal housing and environmental conditions}

Trials were conducted under supervision of the veterinary office of the Bavarian government. Animal handling and care were in accordance with the German laws for animal protection. To determine the effects of increasing dietary Leu supply to pigs fed diets without surpluses of either Ile or Val, two growth assays were conducted, each with fortyeight crossbred pigs (German Landrace $\times$ Piétrain). The pigs were raised at the same commercial plant and had an average age of 28 (SD 1) d. The initial body weight was 8.93 (SD $0.79) \mathrm{kg}$ (expt 1) and 8.40 (SD 0.91) kg (expt 2). The ratio between castrated male and female pigs was balanced.
Pigs were individually housed in pens $(60 \times 100 \mathrm{~cm}$, plastic slats) in an environmentally controlled building. During the experimental period of $34 \mathrm{~d}$, the room temperature was incrementally reduced from $29^{\circ} \mathrm{C}$ at the beginning to $25^{\circ} \mathrm{C}$ by the end of the experiment. Full light was provided from 07.00 to 17.00 hours, followed by half-light. Animals had ad libitum access to food and water. Animals and feeders were monitored twice daily.

\section{Diets and experimental design}

Pigs were allotted to one of six dietary treatments on the basis of their weight. Sex and ancestry were equalised across treatments in a randomised block design. Basal diets were mainly based on barley and wheat (Table 1). Maize gluten feed and soyabean meal were used as protein sources. Na-L-glutamate was included to enable the composition of isonitrogenous diets (analysed crude protein: $17.99-18.36 \%$ in expt 1; $17 \cdot 67-18.31 \%$ in expt 2). The energy content was kept constant at $13.5 \mathrm{MJ}$ metabolisable energy $/ \mathrm{kg}$ (calculated). Diets were supplemented with essential crystalline amino acids (other than the BCAA) to meet ideal protein conditions ${ }^{(11)}$. Tryptophan supplementation was increased to a standardised ileal digestible (SID) tryptophan:lysine ratio of $22 \%$. Analysed SID lysine levels ranged from 1.12 to $1.14 \%$ in expt 1 , and from 1.11 to $1.12 \%$ in expt 2 . Levels of SID amino acids

Table 1. Composition of experimental diets used in expt 1 and expt 2

\begin{tabular}{|c|c|c|c|c|c|c|c|c|c|c|c|c|}
\hline & \multicolumn{6}{|c|}{ Expt 1} & \multicolumn{6}{|c|}{ Expt 2} \\
\hline & L100 & L150 & L175 & L200 & $L+V 200$ & $\mathrm{PC}$ & L100 & L150 & L175 & L200 & $L+1200$ & PC \\
\hline \multicolumn{13}{|c|}{ Ingredient (g/kg) } \\
\hline Barley & 267.9 & 273.6 & $276 \cdot 4$ & $279 \cdot 3$ & 287.5 & $269 \cdot 0$ & $267 \cdot 6$ & 273.0 & $275 \cdot 7$ & $278 \cdot 4$ & $284 \cdot 7$ & $268 \cdot 8$ \\
\hline Wheat & 234.7 & 234.7 & 234.7 & 234.7 & $234 \cdot 7$ & $235 \cdot 0$ & 234.7 & 234.7 & 234.7 & 234.7 & 234.7 & $234 \cdot 7$ \\
\hline MGF & $150 \cdot 0$ & $150 \cdot 0$ & $150 \cdot 0$ & $150 \cdot 0$ & $150 \cdot 0$ & $150 \cdot 0$ & $150 \cdot 0$ & $150 \cdot 0$ & $150 \cdot 0$ & $150 \cdot 0$ & $150 \cdot 0$ & $150 \cdot 0$ \\
\hline SBM & $132 \cdot 1$ & $131 \cdot 0$ & $130 \cdot 4$ & $129 \cdot 8$ & $128 \cdot 3$ & $132 \cdot 0$ & $133 \cdot 0$ & $133 \cdot 0$ & 133.0 & 133.0 & 133.0 & $133 \cdot 0$ \\
\hline Maize & $100 \cdot 0$ & $100 \cdot 0$ & $100 \cdot 0$ & $100 \cdot 0$ & $100 \cdot 0$ & $100 \cdot 0$ & $100 \cdot 0$ & $100 \cdot 0$ & $100 \cdot 0$ & $100 \cdot 0$ & $100 \cdot 0$ & $100 \cdot 0$ \\
\hline SGBM & $15 \cdot 0$ & $15 \cdot 0$ & $15 \cdot 0$ & $15 \cdot 0$ & $15 \cdot 0$ & $15 \cdot 0$ & $15 \cdot 0$ & $15 \cdot 0$ & $15 \cdot 0$ & $15 \cdot 0$ & $15 \cdot 0$ & $15 \cdot 0$ \\
\hline Soya oil & $33 \cdot 1$ & $30 \cdot 5$ & $29 \cdot 2$ & $28 \cdot 0$ & $25 \cdot 2$ & $32 \cdot 4$ & $32 \cdot 9$ & $30 \cdot 4$ & $29 \cdot 1$ & $27 \cdot 9$ & $24 \cdot 8$ & 32.5 \\
\hline $\mathrm{V}+\mathrm{M}^{*}$ & $25 \cdot 3$ & $25 \cdot 3$ & $25 \cdot 3$ & $25 \cdot 2$ & $25 \cdot 1$ & $25 \cdot 3$ & $25 \cdot 3$ & $25 \cdot 3$ & $25 \cdot 2$ & $25 \cdot 1$ & $25 \cdot 0$ & $25 \cdot 3$ \\
\hline L-Lys-.HCl & $7 \cdot 3$ & $7 \cdot 3$ & $7 \cdot 3$ & $7 \cdot 3$ & $7 \cdot 3$ & $7 \cdot 3$ & $7 \cdot 2$ & $7 \cdot 2$ & $7 \cdot 2$ & $7 \cdot 2$ & $7 \cdot 2$ & $7 \cdot 2$ \\
\hline DL-Met & $2 \cdot 2$ & $2 \cdot 2$ & $2 \cdot 2$ & $2 \cdot 2$ & $2 \cdot 2$ & $2 \cdot 2$ & $2 \cdot 2$ & $2 \cdot 1$ & $2 \cdot 1$ & $2 \cdot 1$ & $2 \cdot 1$ & $2 \cdot 2$ \\
\hline L-Thr & $2 \cdot 8$ & $2 \cdot 8$ & $2 \cdot 8$ & $2 \cdot 8$ & $2 \cdot 8$ & $2 \cdot 8$ & $2 \cdot 7$ & $2 \cdot 7$ & $2 \cdot 7$ & $2 \cdot 7$ & $2 \cdot 7$ & 2.7 \\
\hline L-Trp & $1 \cdot 0$ & $1 \cdot 0$ & 1.0 & $1 \cdot 0$ & $1 \cdot 0$ & $1 \cdot 0$ & 1.0 & $1 \cdot 0$ & $1 \cdot 0$ & $1 \cdot 0$ & $1 \cdot 0$ & 1.0 \\
\hline L-Leu & 0.9 & $6 \cdot 4$ & $9 \cdot 2$ & 11.9 & 11.9 & 0.9 & 0.7 & $6 \cdot 1$ & 8.9 & $11 \cdot 6$ & $11 \cdot 6$ & 0.7 \\
\hline L-Ile & - & - & - & - & - & 1.4 & 1.6 & $1 \cdot 6$ & $1 \cdot 6$ & 1.5 & $8 \cdot 1$ & 1.6 \\
\hline L-Val & 1.4 & 1.4 & 1.4 & 1.4 & $9 \cdot 0$ & 1.4 & 0.2 & 0.2 & 0.2 & 0.2 & 0.1 & $1 \cdot 3$ \\
\hline Na-L-Glu & $26 \cdot 3$ & $18 \cdot 8$ & $15 \cdot 1$ & 11.4 & - & $24 \cdot 3$ & $25 \cdot 9$ & $17 \cdot 7$ & $13 \cdot 6$ & 9.6 & - & $24 \cdot 0$ \\
\hline \multicolumn{13}{|c|}{ Analysed composition (g/kg) } \\
\hline $\mathrm{CP}$ & $181 \cdot 4$ & $184 \cdot 1$ & $182 \cdot 9$ & $183 \cdot 6$ & $179 \cdot 9$ & $180 \cdot 8$ & $181 \cdot 2$ & $176 \cdot 7$ & $179 \cdot 6$ & $178 \cdot 6$ & $183 \cdot 1$ & $181 \cdot 8$ \\
\hline Lys & $12 \cdot 4$ & $12 \cdot 4$ & $12 \cdot 6$ & $12 \cdot 6$ & $12 \cdot 4$ & $12 \cdot 4$ & $12 \cdot 3$ & $12 \cdot 4$ & $12 \cdot 3$ & $12 \cdot 4$ & $12 \cdot 4$ & $12 \cdot 4$ \\
\hline Met + Cys & $7 \cdot 7$ & $7 \cdot 7$ & $7 \cdot 6$ & $7 \cdot 6$ & $7 \cdot 6$ & $7 \cdot 7$ & $7 \cdot 8$ & $7 \cdot 6$ & $7 \cdot 6$ & $7 \cdot 6$ & $7 \cdot 8$ & $7 \cdot 7$ \\
\hline Thr & $7 \cdot 9$ & $8 \cdot 0$ & $8 \cdot 0$ & $8 \cdot 1$ & $8 \cdot 0$ & $8 \cdot 0$ & 8.0 & 7.9 & 7.9 & $8 \cdot 0$ & $8 \cdot 1$ & 8.0 \\
\hline Trp & $2 \cdot 8$ & $2 \cdot 8$ & $2 \cdot 8$ & $2 \cdot 8$ & $2 \cdot 7$ & $2 \cdot 8$ & $2 \cdot 7$ & $2 \cdot 7$ & $2 \cdot 7$ & $2 \cdot 8$ & $2 \cdot 8$ & $2 \cdot 7$ \\
\hline $\mathrm{Ile}$ & $5 \cdot 8$ & 5.9 & 5.9 & $5 \cdot 9$ & $5 \cdot 7$ & $7 \cdot 2$ & $7 \cdot 3$ & $7 \cdot 2$ & $7 \cdot 2$ & $7 \cdot 2$ & $13 \cdot 9$ & $7 \cdot 3$ \\
\hline Leu & $13 \cdot 3$ & $18 \cdot 6$ & $21 \cdot 3$ & $23 \cdot 9$ & $23 \cdot 7$ & $13 \cdot 1$ & $12 \cdot 9$ & $18 \cdot 1$ & $20 \cdot 9$ & 23.5 & $24 \cdot 1$ & 12.9 \\
\hline Val & $8 \cdot 6$ & $8 \cdot 7$ & $8 \cdot 6$ & $8 \cdot 6$ & $15 \cdot 6$ & 8.5 & 7.5 & $7 \cdot 4$ & $7 \cdot 4$ & $7 \cdot 3$ & $7 \cdot 4$ & 8.5 \\
\hline Phe + Tyr & $13 \cdot 0$ & $12 \cdot 6$ & $12 \cdot 6$ & $12 \cdot 6$ & $12 \cdot 5$ & $12 \cdot 7$ & $12 \cdot 5$ & $12 \cdot 4$ & $12 \cdot 4$ & $12 \cdot 2$ & $12 \cdot 4$ & $12 \cdot 5$ \\
\hline His & $4 \cdot 0$ & $4 \cdot 0$ & $4 \cdot 0$ & $4 \cdot 0$ & 3.9 & $4 \cdot 0$ & $3 \cdot 9$ & $3 \cdot 8$ & $3 \cdot 9$ & $3 \cdot 8$ & $3 \cdot 9$ & 3.9 \\
\hline
\end{tabular}

MGF, maize gluten feed; SBM, soyabean meal; SGBM, sugarbeet molasses; $V+M$, vitamin and mineral mixture; $C P$, crude protein.

*Per kilogram of diet: retinol, $1.5 \mathrm{mg}$; cholecalciferol, $0.13 \mathrm{mg}$; DL- $\alpha$-tocopheryl acetate, $30 \mathrm{mg}$; menadione, $150 \mu \mathrm{g}$; thiamin, $3 \mathrm{mg}$; riboflavin, $3 \mathrm{mg}$; pyridoxine, $3 \mathrm{mg}$; cyanocobalamin, $18 \mu \mathrm{g}$; nicotinic acid, $25 \mathrm{mg}$; pantothenic acid, $15 \mathrm{mg}$; biotin, $50 \mu \mathrm{g}$; folic acid, $300 \mu \mathrm{g}$; choline (as choline chloride), $300 \mathrm{mg}$; Ca, $4.9 \mathrm{~g}$; P, $1.4 \mathrm{~g}$; $\mathrm{Na}, 0.75 \mathrm{~g}$; $\mathrm{Mg}, 0.3 \mathrm{~g}$; Zn (zinc oxide), $70 \mathrm{mg}$; Fe (ferrous sulphate monohydrate), $100 \mathrm{mg}$; iodine (calcium iodate), $1.2 \mathrm{mg}$; Se (sodium selenite pentahydrate), $0.26 \mathrm{mg}$; Cu (copper sulphate pentahydrate), $10.0 \mathrm{mg}$; Mn (manganese oxide), $40.0 \mathrm{mg}$. 
in mixed diets were calculated by multiplication of the analysed amino acid contents of each feed ingredient with the estimates of standardised ileal amino acid digestibility ${ }^{(12)}$. These estimates consider basal endogenous amino acid losses and are calculated as follows ${ }^{(13)}$.

$$
\begin{aligned}
\operatorname{SID}(\%)= & \{\text { [amino acid intake }- \text { (ileal amino acid outflow }) \\
& - \text { basal endogenous ileal amino acid losses }] / \\
& \text { amino acid intake }\} \times 100 .
\end{aligned}
$$

All diets were supplemented with vitamins and minerals to meet or exceed the requirements for $10-20 \mathrm{~kg} \mathrm{pigs}^{(14)}$.

In expt 1, the effects of increasing the dietary Leu supply in pigs fed diets with a constant Ile supply of $5.0 \mathrm{~g} \mathrm{SID} \mathrm{Ile/kg} \mathrm{of}$ diet were estimated. Dietary Leu level of the basal group was $11.5 \mathrm{~g} \mathrm{SID} \mathrm{Leu} / \mathrm{kg}$ and was considered as $100 \%$ (treatment: L100). In treatments L150, L175 and L200, the Leu supply was then increased to give dietary Leu levels of 150,175 and $200 \%$ relative to treatment L100. Ratios of SID Leu:Ile were $2.33,3.43,3.98$ and 4.49 in treatments L100, L150, L175 and L200, respectively. In treatment L + V 200, the Leu and Val supplies were doubled (relative to treatment L100) to determine the effects of a simultaneous excess of Leu and Val. With the last treatment, it should be tested whether the chosen Ile level of $5.0 \mathrm{~g}$ SID Ile/ $\mathrm{kg}$ was first limiting and surpluses of Ile were avoided, which is a precondition to get meaningful Ile:Leu ratios. Diet composition of this positive control (PC) was equal to the basal treatment L100, but the Ile supply was increased to $6 \cdot 3 \mathrm{~g}$ SID Ile $/ \mathrm{kg}$.

In expt 2, the effects of increasing the dietary Leu supply in pigs fed diets with a constant Val level of $6 \cdot 2 \mathrm{~g} \mathrm{SID} \mathrm{Val} / \mathrm{kg}$ of diet were estimated. In the basal treatment, the Leu supply was $11 \cdot 1 \mathrm{~g} \mathrm{SID} \mathrm{Leu} / \mathrm{kg}$ and was considered as $100 \%$ (treatment L100). In the following treatments, the Leu supply was increased by L-Leu supplementation to give 150 (L150), 175 (L175) and $200 \%$ (L200) of the Leu level of treatment L100. SID Leu:Val ratios were $1.79,2.63,3.08$ and 3.55 in treatments L100, L150, L175 and L200, respectively. In treatment L + I 200, the Leu and Ile supplies were doubled (relative to treatment L100) to determine the effects of a simultaneous excess of Leu and Ile. Again, the last treatment was a PC. Diet composition was equal to treatment L100, but the Val supply was increased to $7 \cdot 3 \mathrm{~g} \mathrm{SID} \mathrm{Val} / \mathrm{kg}$.

\section{Sampling}

Trials were terminated on day 34 , when the pigs were fasted for $2.5 \mathrm{~h}$. Afterwards, two blood samples per pig were taken via jugular vein puncture. The first sample was used to determine plasma-free amino acids $(9 \mathrm{ml}$, S-Monovette, Li-Heparin, Sarstedt, Nümbrecht, Germany). The second sample was used to determine serum BCKA ( $9 \mathrm{ml}$, GelS-Monovette, Sarstedt, Nümbrecht, Germany). The samples were cooled by ice water. Plasma and serum were obtained by centrifugation $\left(20 \mathrm{~min}, 800 \mathrm{~g}\right.$ ), and stored at $-80^{\circ} \mathrm{C}$.

After blood sampling, the pigs remained for $3 \mathrm{~d}$ at the experimental piggery, where the feeding diet regimen was switched to three meals per day. The daily amount of feed was calculated for each individual pig by multiplication of its metabolic body weight with a treatment-specific factor of average daily feed intake per kilogram metabolic body weight, estimated for the last experimental week. On day 38 , all pigs of expt $1+2$ undergoing treatments L100, L150 and L200 were killed by captive bolt pistol and exsanguinated by transection of the carotid arteries in randomised order. All pigs were fed $1 / 3$ of their daily feed amount at 07.00 hours. The first pig was killed at 09.30 hours. For every delay, the following pigs received an extra meal (1/24 of the daily feed amount per $\mathrm{h}$ of delay), at $2.5 \mathrm{~h}$ before killing, to ensure comparable postprandial conditions. After exsanguinations, samples of skeletal muscle (musculus longissimus dorsi, seventh rib), heart, liver, spleen, jejunum and ileum (mid parts) were removed and quick frozen in liquid nitrogen until storage at $-80^{\circ} \mathrm{C}$. Response variables were daily gain, daily feed intake, feed efficiency, plasma amino acids, serum BCKA, the BCKDH activity in liver samples, mRNA of genes encoding enzymes in BCAA catabolism and mRNA of genes related to GH-IGF-1.

\section{Feed analyses}

Crude protein content was determined using the Kjeldahl procedure $^{(15)}$. Analysis of dietary amino acids was carried out by Ajinomoto Eurolysine S.A.S (Paris, France). Amino acid contents were analysed by ion exchange chromatography after acid hydrolysis with $\mathrm{HCl}\left(6 \mathrm{M} \text {, reflux for } 23 \mathrm{~h} \text { at } 110^{\circ} \mathrm{C}\right)^{(16)}$. Methionine and cysteine were assayed after performic acid oxidation $^{(16)}$. Tryptophan was determined by reversed-phase HPLC and fluorometric detection after alkaline hydrolysis with barium hydroxide $\left(16 \mathrm{~h}, 120^{\circ} \mathrm{C}\right)^{(17)}$.

\section{Plasma-free amino acids}

Plasma proteins were removed by precipitation with salicylsulphonic acid and centrifugation $(11000 \mathrm{~g}, 10 \mathrm{~min})$. After dilution with a lithium acetate solution, the protein-free supernatant was analysed by ion exchange chromatography on an automatic amino acid analyser (LC 3000, Biotronik, Hamburg, Germany) ${ }^{(15)}$.

\section{Branched-chain $\alpha$-keto-acids determination}

BCKA were analysed as reported by Pailla et al. ${ }^{(18)}$. BCKA were derivatised with $o$-phenylenediamine to give fluorescent derivates, which were separated chromatographically on a reversed-phase column (Spherisorb ODS-2, 4.6 ×250 mm, $5 \mu \mathrm{m}$ particles, Waters, Eschborn, Germany) using a binary gradient (L-7100, Merck-Hitachi, Tokyo, Japan). Detection was performed fluorometrically (FL Detector L-7480, Merck-Hitachi). $\alpha$-keto-valerate was used as an internal standard.

\section{Branched-chain $\alpha$-keto acid dehydrogenase activity}

BCKDH activity was assayed spectrophotometrically ${ }^{(19)}$. A frozen tissue sample was pulverised to a fine powder under liquid nitrogen. Thereafter, $0.25 \mathrm{~g}$ of the powder was homogenised (motor driven Tefflon pestle) in ice-cold extraction buffer. Insoluble material was removed by centrifugation $\left(20000 \mathrm{~g}, 5 \mathrm{~min}, 4^{\circ} \mathrm{C}\right)$, and the supernatant was made $9 \%$ $(\mathrm{v} / \mathrm{v})$ in polyethylene glycol. After $20 \mathrm{~min}$ on ice, a second 
centrifugation step $\left(12000 \mathrm{~g}, 10 \mathrm{~min}, 4^{\circ} \mathrm{C}\right)$ was performed, and the pellet dissolved in suspension buffer. BCKDH activity was determined at $30^{\circ} \mathrm{C}$ using $\alpha$-keto-isovalerate (KIV) as substrate, by measuring absorbance at $340 \mathrm{~nm}$ to detect NADH formation. To determine total BCKDH activity, the tissue extract was incubated $\left(20 \mathrm{~min}, 37^{\circ} \mathrm{C}\right)$ with $\lambda$ protein phosphatase before measurement. In contrast to Nakai et al. ${ }^{(19)}$, the assay buffer was made without dihydrolipoamide dehydrogenase.

\section{Total RNA extraction}

Total RNA was extracted with peqGOLD TriFast (PEQLAB Biotechnologie, Erlangen, Germany) that uses a one-step liquid-phase separation using phenol and guanidine isothiocyanate in a single liquid phase. Tissue samples $(50 \mathrm{mg})$ were homogenised using the MagNA Lyser Green beads (Roche Diagnostics, Mannheim, Germany) in the presence of peqGOLD TriFast $(0.5 \mathrm{ml})$. After addition of chloroform $(100 \mu \mathrm{l})$ and centrifugation $(12000 \mathrm{~g}, 15 \mathrm{~min})$, the homogenate was separated into three phases, with the RNA in the upper aqueous phase. The extracted RNA, free of DNA and proteins, was precipitated with isopropanol $(150 \mu \mathrm{l})$ and centrifugation $\left(12000 \mathrm{~g}, 10 \mathrm{~min}, 4^{\circ} \mathrm{C}\right)$. Pellets were washed twice with $250 \mu \mathrm{l}$ of $75 \%(\mathrm{v} / \mathrm{v})$ ethanol at $-20^{\circ} \mathrm{C}$ and centrifugation $(10000 \mathrm{~g}$, $5 \mathrm{~min}, 4^{\circ} \mathrm{C}$ ). RNA was dissolved in $30 \mu \mathrm{l}$ diethyl pyrocarbonate-treated water and stored at $-80^{\circ} \mathrm{C}$.

Liver samples were additionally treated with peqGOLD OptiPure (PEQLAB Biotechnologie) to eliminate polysaccharides. Pellets obtained by extraction with peqGOLD TriFast were mixed with $100 \mu \mathrm{l}$ peqGOLD OptiPure. After centrifugation $\left(3000 \mathrm{~g}, 10 \mathrm{~min}, 4^{\circ} \mathrm{C}\right)$, the supernatant was removed and $100 \mu \mathrm{l} \operatorname{SDS}(0.5 \%(\mathrm{w} / \mathrm{v}), \mathrm{pH} 7)$ was added. After incubation for $5 \mathrm{~min}$ at $55^{\circ} \mathrm{C}, 100 \mu$ l chloroform was added and the mixture was centrifuged $\left(3000 \mathrm{~g}, 5 \mathrm{~min}, 4^{\circ} \mathrm{C}\right)$. Natrium acetate $(2 \mathrm{M}, \mathrm{pH} 5)$ was added to the supernatant to a final concentration of $0 \cdot 2 \mathrm{M}$. RNA was precipitated with isopropanol $(100 \mu \mathrm{l})$. Centrifugation and washing steps were as described for the extraction. Pellets were dissolved in $60 \mu \mathrm{l}$ diethyl pyrocarbonate-treated water.

RNA quantity was determined photometrically (Nanodrop 1000, PEQLAB Biotechnologie) and purity calculated from the $260 / 280 \mathrm{~nm}$ absorbance ratio. All working solutions were diluted to a RNA concentration of $10 \mathrm{ng} / \mu \mathrm{l}$.

\section{RNA quality}

Integrity of RNA was analysed for six random samples per tissue and trial using the RNA 6000 Nano assay (Agilent Technology, Palo Alto, CA, USA) and the 2100 Bioanalyser (Agilent Technology). The RNA integrity number served as an RNA quality parameter ranging from one (the most degraded profile) to ten (the most intact profile).

\section{Primer design}

Primers were designed using published RNA sequences of pigs (http://www.ncbi.nlm.nih.gov/entrez/query.fcgi), if available. Otherwise, they were designed as nested primers from homologous regions of cattle, human and rat genes. Primer design accounted for primer-dimer formation, self-priming and primer annealing temperature $\left(60^{\circ} \mathrm{C}\right)$ (http://fokker.wi. mit.edu/primer3/input.htm). Primers were synthesised by Eurofins MWG Operon (Ebersberg, Germany) and are listed in Table 2. Primer testing included different annealing temperatures and product validation via agarose gel electrophoresis for four random samples and a negative control for each primer set.

\section{PCR analysis}

Quantitative real time PCR was conducted using a SuperScript III Platinum SYBR Green One-Step quantitative real time PCR Kit (Invitrogen Corporation, Carlsbad, CA, USA). For each sample, $5 \mu 12 X$ SYBR Green Reaction Mix, $0.5 \mu l$ forward primer $(10 \mu \mathrm{M}), 0.5 \mu \mathrm{l}$ reverse primer $(10 \mu \mathrm{M})$ and $0.2 \mu \mathrm{l}$ SuperScript III RT/Platinum Taq Mix were mixed, and 3.8 $\mu \mathrm{l}$ template (total RNA concentration: $10 \mathrm{ng} / \mu \mathrm{l}$ ) was added. quantitative real time PCR was performed with a RotorGene 6000 (Analysis Software 6.0; Corbett Life Science, Sydney, NSW, Australia) using the following protocol: hold step $\left(55^{\circ} \mathrm{C}, 3 \mathrm{~min}\right)$; denaturation step $\left(95^{\circ} \mathrm{C}, 5 \mathrm{~min}\right)$; cycling $\left(95^{\circ} \mathrm{C}, 15 \mathrm{~s} ; 60^{\circ} \mathrm{C}, 10 \mathrm{~s} ; 68^{\circ} \mathrm{C}, 20 \mathrm{~s} ; 40\right.$ cycles $)$; hold step $\left(40^{\circ} \mathrm{C}, 1 \mathrm{~min}\right)$; melting curve analysis.

The products obtained by quantitative real time PCR were validated by $1.8 \%$ agarose gel electrophoresis at $90 \mathrm{~V}$ for 30 min. After gel extraction (Wizard SV Gel and PCR Clean-Up system, Promega Cooperation, Madison, WI, USA), sequencing was performed by the Department Biology Genomics Service unit at the Ludwig-Maximilians-Universität München. Nested primers were designed from the determined sequences.

\section{Statistical analyses}

Data were analysed by ANOVA using the mixed procedure of Statistical Analysis Systems statistical software package version 9.1. (SAS Institute, Cary, NC, USA), with individual pigs as experimental units. The model included treatment and sex as fixed and litter as random effects. Initial body weight was used as a covariate. Contrasts were performed to determine the linear and quadratic effects of an increasing dietary Leu supply ${ }^{(20)}$. The integrated matrix language procedure was used to generate orthogonal polynomial coefficients, and the mixed procedure was used to compute orthogonal polynomial sums of squares. $P$-values for treatment are given in the tables. The effects of doubling the Val or Ile supply at high levels of dietary Leu were tested for significance using the Tukey adjustment (expt 1: L200 v. L+V 200; expt 2: L200 v. L + I 200). The effects of the PC were tested for significance using the Tukey adjustment (L100 v. PC).

mRNA expression data were analysed using the relative quantification method that describes the change in target gene expression relative to the control group. $\beta$-actin, ubiquitin and glyceraldehyde-3-phosphate dehydrogenase genes were used as normalising internal controls for the amount of RNA added to reverse transcription reactions. Internal control gene expression was analysed for every tissue and every sample. For normalisation, the tissue- and sample-specific arithmetic means of the three internal control genes served as a control gene index. Cycle thresholds of the target 
Table 2. Sequences of primers used for quantitative real time-PCR and product sizes

\begin{tabular}{|c|c|c|c|}
\hline Gene & Primer & Sequence $\left(5^{\prime}-3^{\prime}\right)$ & Size (bps) \\
\hline$\beta$-Actin & $\begin{array}{l}\text { forward } \\
\text { reverse }\end{array}$ & $\begin{array}{l}\text { AAC TCC ATC ATG AAG TGT GAC G } \\
\text { GAT CCA CAT CTG CTG GAA GG }\end{array}$ & 233 \\
\hline Ubiquitin & $\begin{array}{l}\text { forward } \\
\text { reverse }\end{array}$ & $\begin{array}{l}\text { AGA TCC AGG ATA AGG AAG GCA T } \\
\text { GCT CCA CCT CCA GGG TGA T }\end{array}$ & 198 \\
\hline GAPDH & $\begin{array}{l}\text { forward } \\
\text { reverse }\end{array}$ & $\begin{array}{l}\text { AGC AAT GCC TCC TGT ACC AC } \\
\text { AAG CAG GGA TGA TGT TCT GG }\end{array}$ & 187 \\
\hline BCATm & $\begin{array}{l}\text { forward } \\
\text { reverse }\end{array}$ & $\begin{array}{l}\text { GCC TGA AGG CGT ACA AAG G } \\
\text { GAT GCA CTC CAG CAA CTC G }\end{array}$ & 130 \\
\hline $\mathrm{BCKDH} \mathrm{E} 1 \alpha$ & $\begin{array}{l}\text { forward } \\
\text { reverse }\end{array}$ & $\begin{array}{l}\text { CCA GAT GCC CGT CCA CTA C } \\
\text { CCC CCT CTC CGA AGT AAC AG }\end{array}$ & 152 \\
\hline BCKDH E1 $\beta$ & $\begin{array}{l}\text { forward } \\
\text { reverse }\end{array}$ & $\begin{array}{l}\text { GCC GAA GTC ATC CAA GAA GG } \\
\text { TGA CCT CAC AGG ACA CTC CAA G }\end{array}$ & 118 \\
\hline BCKDH E2 & $\begin{array}{l}\text { forward } \\
\text { reverse }\end{array}$ & $\begin{array}{l}\text { ACG ATA CTG CTT ATG TGG GAA AG } \\
\text { TGT GGC CCT TTA TCT CTT GG }\end{array}$ & 128 \\
\hline BCKDK & $\begin{array}{l}\text { forward } \\
\text { reverse }\end{array}$ & $\begin{array}{l}\text { TCC GAC CAT GAT GCT CTA TTC } \\
\text { GAA GTC CTT GAT GCG GTG AG }\end{array}$ & 114 \\
\hline 4-HPPD & $\begin{array}{l}\text { forward } \\
\text { reverse }\end{array}$ & $\begin{array}{l}\text { GTC TTC TCC TCT GCC CTC AA } \\
\text { GCA AA TTC ACC TTC CCA AAC }\end{array}$ & 193 \\
\hline GHR & $\begin{array}{l}\text { forward } \\
\text { reverse }\end{array}$ & $\begin{array}{l}\text { ATG ATG CTG CCC CTG CTA } \\
\text { AAA GGA CCA CAC TCC CTG CT }\end{array}$ & 194 \\
\hline IGFBP-3 & $\begin{array}{l}\text { forward } \\
\text { reverse }\end{array}$ & $\begin{array}{l}\text { TCC AAG CGC GAG ACG GGA TA } \\
\text { TCG CAG TTG GGG ATG TGG AT }\end{array}$ & 113 \\
\hline IGFALS & $\begin{array}{l}\text { forward } \\
\text { reverse }\end{array}$ & $\begin{array}{l}\text { CGA CGA CTA CAC GGA CGA G } \\
\text { CGA GGT GCA GGT GGT ACA G }\end{array}$ & 241 \\
\hline IGFR & $\begin{array}{l}\text { forward } \\
\text { reverse }\end{array}$ & $\begin{array}{l}\text { GGG GAA TGG AGT GCT GTA TG } \\
\text { CTG GTC TCA GGC TCA TCT TTG }\end{array}$ & 185 \\
\hline IGF-1 & $\begin{array}{l}\text { forward } \\
\text { reverse }\end{array}$ & $\begin{array}{l}\text { CTT CAG TTC GTG TGC GGA GAC A } \\
\text { GGA AGC AGC ACT CAT CCA CGA T }\end{array}$ & 109 \\
\hline
\end{tabular}

GAPDH, glyceraldehyde- 3-phosphate dehydrogenase; BCATm, mitochondrial branched-chain amino transferase; BCKDH E1 $\alpha$, branched-chain $\alpha$-keto acid dehydrogenase E1 $\alpha$ subunit; BCKDK, branched-chain $\alpha$-keto acid dehydrogenase kinase; 4-HPPD, 4-hydroxyphenylpyruvate dioxygenase; GHR, growth hormone receptor; IGFBP-3, insulin-like growth factor-binding protein 3; IGFALS, insulin-like growth factor acid labile subunit; IGFR, insulin-like growth factor receptor; IGF-1, insulin-like growth factor 1.

genes were subtracted from the control gene index $\left(\Delta C_{\mathrm{t}}\right)$ for normalisation, and treatment groups were compared to the control group $\left(\Delta \Delta C_{\mathrm{t}},{ }^{(21)}\right)$, using the Statistical Analysis Systems general linear models procedure and the Tukey adjustment. To determine gene expression differences between tissues, the Statistical Analysis Systems general linear models procedure and the Tukey adjustment were applied to $C_{\mathrm{t}}$ values.

\section{Results}

\section{Performance}

In expt 1 , increasing the dietary Leu supply from treatment L100 to L200 linearly decreased the daily feed intake $(P=0.06)$ and gain $(P=0.05)$ by $14-15 \%$ (Table 3$)$. A regression for the average daily gain $(y)$ as a function of the SID Leu:Ile ratio $(x)$ was estimated as $y=548.5-34 \cdot 2 x$ $\left(R^{2} 0.971 ; P=0.02\right)$. In contrast, no major impact was seen on feed efficiency. Doubling the Val supply at high dietary levels of Leu did not affect the performance $(\mathrm{L}+\mathrm{V} 200 v$. L200; $P>0.05)$. The growth performance of PC was not different from that of L100 (P>0.05).

In expt 2, incrementally increasing Leu supply from L100 to L200 linearly decreased the performance parameter in a dose-dependent manner $(P<0.01$; Table 4$)$. The daily feed intake, daily gain and feed efficiency decreased by 30,38 and $11 \%$, respectively. A regression for the average daily gain $(y)$ as a function of the SID Leu:Val ratio $(x)$ was estimated as $y=538.4-84.7 x\left(R^{2} \quad 0.955 ; \quad P=0.02\right)$. In treatment L + I 200, doubling the Ile supply did not affect the performance relative to L200. In PC, increasing the Val supply significantly $(P<0.05)$ increased the animals performance. Compared to L100, the daily feed intake and gain of PC were increased by 38 and $43 \%$, respectively.

\section{Plasma metabolites}

In expt 1 , increasing the dietary Leu supply increased plasma Leu levels linearly $(P<0.01)$ and quadratically $(P=0.03)$, and the serum $\alpha$-keto-isocaproate (KIC) levels linearly $(P<0 \cdot 01)$, in a dose-dependent manner (Table 5). Doubling the Leu supply increased plasma Leu levels by $64 \%$ and serum KIC levels by $45 \%$. Plasma levels of histidine, threonine and serine increased linearly $(P<0.01)$, and plasma methionine and proline were influenced quadratically $(P=0.03)$. In contrast, plasma Val and serum KIV levels decreased linearly $(P<0.01)$ and quadratically $(P<0.01)$ up to 60 and $72 \%$, respectively. However, the plasma Ile and serum $\alpha$-keto $\beta$-methylvalerate (KMV) levels remained unaffected by increasing Leu supply $(P>0 \cdot 05)$.

Doubling the dietary Val supply at high dietary levels of Leu in L + V 200 increased plasma Val levels 4-fold $(P<0.05)$ and serum KIV levels 5.8-fold $(P<0.05)$, but decreased plasma glutamic acid by $32 \%(P<0.05)$ compared to $\mathrm{L} 200$.

Compared to L100, increasing the dietary Ile supply in PC significantly $(P<0.05)$ increased the plasma Ile and serum 
Table 3. Effects of increasing leucine supply and of simultaneous leucine and valine excess on the performance of weaned pigs fed diets first limiting in isoleucine (expt $1 ; n 8)^{*}$

(Mean values with their standard errors)

\begin{tabular}{|c|c|c|c|c|c|c|c|c|}
\hline & \multicolumn{6}{|c|}{ Treatment } & \multirow{3}{*}{\multicolumn{2}{|c|}{$P$ valuest }} \\
\hline & L100 & L150 & L175 & L200 & $L+V 200$ & $\mathrm{PC}$ & & \\
\hline & \multicolumn{6}{|c|}{ SID Leu:lle } & & \\
\hline & $2 \cdot 33$ & 3.43 & 3.98 & 4.49 & - & - & Linear & Quadratic \\
\hline \multicolumn{9}{|l|}{ IBW (kg) } \\
\hline Mean & 8.94 & 8.94 & 8.93 & 8.93 & 8.93 & 8.93 & - & - \\
\hline SE & 0.30 & 0.30 & 0.37 & 0.23 & 0.28 & 0.27 & & \\
\hline \multicolumn{9}{|c|}{ FBW (kg) } \\
\hline Mean & $24 \cdot 83$ & $23 \cdot 87$ & $22 \cdot 81$ & $22 \cdot 44$ & $21 \cdot 11$ & $25 \cdot 19$ & 0.05 & 0.93 \\
\hline SE & $1 \cdot 23$ & 1.05 & $1 \cdot 27$ & $1 \cdot 13$ & 0.68 & 0.47 & & \\
\hline \multicolumn{9}{|l|}{$\mathrm{FI}(\mathrm{g} / \mathrm{d})$} \\
\hline Mean & 646 & 611 & 572 & 558 & 510 & 660 & 0.06 & 0.93 \\
\hline SE & 48 & 36 & 46 & 47 & 32 & 22 & & \\
\hline \multicolumn{9}{|c|}{ Gain (g/d) } \\
\hline Mean & 468 & 439 & 408 & 397 & 358 & 478 & 0.05 & 0.93 \\
\hline SE & 31 & 24 & 31 & 33 & 20 & 18 & & \\
\hline \multicolumn{9}{|c|}{ G:F (g/kg) } \\
\hline Mean & 727 & 722 & 716 & 715 & 706 & 724 & 0.31 & 0.99 \\
\hline SE & 11 & 12 & 10 & 13 & 18 & 12 & & \\
\hline
\end{tabular}

SID, standardised ileal digestible; IBW, initial body weight; FBW, final body weight; FI, feed intake; G:F, gain to feed

${ }^{*}$ For details of animals and procedures, see Materials and methods.

†Polynomial orthogonal contrasts were estimated for L100-L200.

KMV levels 4.6- and 5-fold, respectively. In contrast, serum KIV levels decreased by $26 \%(P<0.05)$.

In expt 2 , increasing the dietary supply of Leu increased plasma Leu linearly $(P<0.01)$ and serum KIC linearly $(P<0.01)$ and quadratically $(P=0.04$; Table 6$)$. Doubling the dietary Leu supply increased the plasma Leu and serum KIC levels by 59 and $49 \%$, respectively. In contrast, plasma Ile and serum KMV levels decreased linearly $(P<0 \cdot 01)$ and quadratically $(P=0.03)$ up to 69 and $66 \%$, respectively. Plasma levels of aspartic acid $(P<0.01)$ and glutamine $(P<0.05)$ also decreased linearly, whereas histidine $(P<0.01)$ and phenylalanine $(P<0.05)$ increased linearly (data not shown). Plasma Val levels were influenced quadratically $(P=0.03)$ and serum KIV levels increased linearly $(P<0.05)$.

Table 4. Effects of increasing leucine supply and of simultaneous leucine and isoleucine excess on the performance of weaned pigs fed diets first limiting in valine (expt $2 ; n 8) \dagger$

(Mean values with their standard errors)

\begin{tabular}{|c|c|c|c|c|c|c|c|c|}
\hline & \multicolumn{6}{|c|}{ Treatment } & \multirow{3}{*}{\multicolumn{2}{|c|}{$P$ values $\ddagger$}} \\
\hline & L100 & L150 & L175 & L200 & $L+1200$ & $P C$ & & \\
\hline & \multicolumn{6}{|c|}{ SID Leu:Val } & & \\
\hline & 1.79 & 2.63 & 3.08 & 3.55 & - & - & Linear & Quadratic \\
\hline \multicolumn{9}{|l|}{ IBW (kg) } \\
\hline Mean & 8.67 & 8.66 & 8.65 & 8.66 & $8 \cdot 71$ & 8.65 & - & - \\
\hline SE & 0.34 & 0.52 & 0.27 & 0.20 & 0.42 & 0.32 & & \\
\hline \multicolumn{9}{|l|}{ FBW (kg) } \\
\hline Mean & $22 \cdot 29$ & $18 \cdot 88$ & $18 \cdot 19$ & $17 \cdot 25$ & $17 \cdot 36$ & $28 \cdot 08^{*}$ & $<0.01$ & 0.18 \\
\hline SE & 0.85 & 0.91 & $1 \cdot 16$ & 1.04 & $1 \cdot 36$ & $1 \cdot 29$ & & \\
\hline \multicolumn{9}{|l|}{$\mathrm{FI}(\mathrm{g} / \mathrm{d})$} \\
\hline Mean & 568 & 446 & 420 & 400 & 388 & $786^{*}$ & $<0.01$ & 0.14 \\
\hline SE & 36 & 28 & 40 & 50 & 51 & 48 & & \\
\hline \multicolumn{9}{|l|}{ Gain (g/d) } \\
\hline Mean & 400 & 299 & 279 & 252 & 255 & $570^{*}$ & $<0.01$ & 0.18 \\
\hline SE & 22 & 22 & 31 & 30 & 37 & 30 & & \\
\hline \multicolumn{9}{|l|}{$\mathrm{G}: F(\mathrm{~g} / \mathrm{kg})$} \\
\hline Mean & 707 & 670 & 662 & 630 & 651 & 723 & $<0.01$ & 0.80 \\
\hline SE & 14 & 16 & 25 & 18 & 19 & 15 & & \\
\hline
\end{tabular}

SID, standardised ileal digestible; IBW, initial body weight; FBW, final body weight; FI, feed intake; G:F, gain to feed. Mean values were significantly different from those of the L100 group: ${ }^{\star} P<0.05$.

†For details of animals and procedures, see Materials and methods.

$\ddagger$ Polynomial orthogonal contrasts were estimated for L100 to L200. 
Table 5. Effects of increasing leucine supply and of simultaneous leucine and isoleucine excess on plasma-free amino acids and serum branchedchain $\alpha$-keto-acids of weaned pigs fed diets first limiting in isoleucine (expt $1 ; n 8) \ddagger$

(Mean values with their standard errors)

\begin{tabular}{|c|c|c|c|c|c|c|c|c|c|c|c|c|c|c|}
\hline & \multicolumn{12}{|c|}{ Treatment } & & \\
\hline & \multicolumn{2}{|c|}{ L100 } & \multicolumn{2}{|c|}{ L150 } & \multicolumn{2}{|c|}{ L175 } & \multicolumn{2}{|c|}{ L200 } & \multicolumn{2}{|c|}{$\mathrm{L}+\mathrm{V} 200$} & \multicolumn{2}{|c|}{ PC } & & \\
\hline & \multicolumn{12}{|c|}{ SID Leu:Ile } & & \\
\hline & \multicolumn{2}{|c|}{$2 \cdot 33$} & \multicolumn{2}{|c|}{3.43} & \multicolumn{2}{|c|}{3.98} & \multicolumn{2}{|c|}{4.49} & \multicolumn{2}{|c|}{-} & \multicolumn{2}{|c|}{-} & \multicolumn{2}{|c|}{$P$ values§ } \\
\hline & Mean & SE & Mean & SE & Mean & SE & Mean & SE & Mean & SE & Mean & SE & Linear & Quadratic \\
\hline \multicolumn{15}{|c|}{ Amino acids $(\mu \mathrm{mol} / \mathrm{l})$} \\
\hline lle & 28 & 6 & 27 & 5 & 28 & 4 & 31 & 5 & 27 & 4 & $130 \dagger$ & 9 & 0.82 & 0.67 \\
\hline Leu & 133 & 10 & 149 & 8 & 174 & 15 & 218 & 8 & 200 & 35 & 143 & 13 & $<0.01$ & 0.03 \\
\hline Val & 236 & 14 & 98 & 6 & 94 & 8 & 103 & 9 & $417^{*}$ & 49 & 218 & 14 & $<0.01$ & $<0.01$ \\
\hline ¿EAS & 1057 & 75 & 956 & 46 & 991 & 75 & 1171 & 50 & 1424 & 145 & 1059 & 64 & 0.24 & $<0.01$ \\
\hline$\Sigma$ NEAS & 3358 & 193 & 3294 & 165 & 3231 & 239 & 3680 & 141 & 3349 & 130 & 3384 & 130 & 0.38 & 0.16 \\
\hline \multicolumn{15}{|c|}{ Branched-chain $\alpha$-keto-acids ( $\mu \mathrm{mol} / \mathrm{l})$} \\
\hline KMV & 5.4 & 1.2 & 5.9 & 1.2 & $5 \cdot 8$ & 1.3 & $5 \cdot 0$ & $1 \cdot 2$ & 4.5 & 1.0 & $26.9+$ & 1.3 & 0.92 & 0.61 \\
\hline $\mathrm{KIC}$ & 33.4 & 2.9 & $43 \cdot 7$ & $2 \cdot 7$ & 44.4 & 2.5 & 48.5 & 3.6 & $45 \cdot 0$ & 5.4 & $28 \cdot 6$ & 1.7 & $<0.01$ & 0.51 \\
\hline KIV & $11 \cdot 6$ & 1.0 & $5 \cdot 1$ & 0.3 & $4 \cdot 1$ & 0.8 & $3 \cdot 3$ & 0.6 & $19 \cdot 3^{*}$ & 1.6 & $8.6 \dagger$ & 0.4 & $<0.01$ & 0.01 \\
\hline
\end{tabular}

SID, standardised ileal digestible; $\Sigma E A S$, sum of the essential amino acids; $\Sigma$ NEAS, sum of the non-essential amino acids; KMV, $\alpha$-keto- $\beta$-methylvalerate; KIC, $\alpha$-ketoisocaproate; KIV, $\alpha$-keto-isovalerate.

Mean values were significantly different from those of the L200 group: ${ }^{\star} P<0.05$.

Mean values were significantly different from those of the $L 100$ group: $\dagger P<0.05$

$\ddagger$ For details of animals and procedures, see Materials and methods.

$\S$ Polynomial orthogonal contrasts were estimated for L100 to L200.

Doubling the dietary Ile supply at high dietary Leu levels increased the plasma Ile and serum KMV levels 2.9- and 2.4-fold $(P<0 \cdot 05)$, respectively (L200 v. L + I 200).

Increasing the dietary Val supply in the PC significantly $(P<0.05)$ increased the plasma Val and serum KIV levels 5.6- and 13.6-fold, respectively, compared to L100. Plasma cysteine levels also increased $(P<0.05)$. In contrast, plasma methionine, phenylalanine, threonine, alanine, asparagine, glycine and serine levels decreased $(P<0.05$; data not shown).
Branched-chain $\alpha$-keto acid dehydrogenase activities in the liver

In expt 1, the total BCKDH activity was not altered by increasing Leu supply (Fig. 1(a)). In contrast, the basal activity (Fig. 1(c)) and the level of activation (Fig. 1(e)) increased linearly $(P<0.01)$ by 165 and $135 \%$, respectively.

In expt 2 , increasing the dietary Leu supply did not affect the total BCKDH activity (Fig. 1(b)). In contrast, the basal activity (Fig. 1(d)) and the corresponding level of activation

Table 6. Effects of increasing leucine supply and of simultaneous leucine and isoleucine excess on plasma-free amino acids and serum branchedchain $\alpha$-keto-acids of weaned pigs fed diets first limiting in valine (expt $2 ; n 8) \ddagger$

(Mean values with their sandard errors)

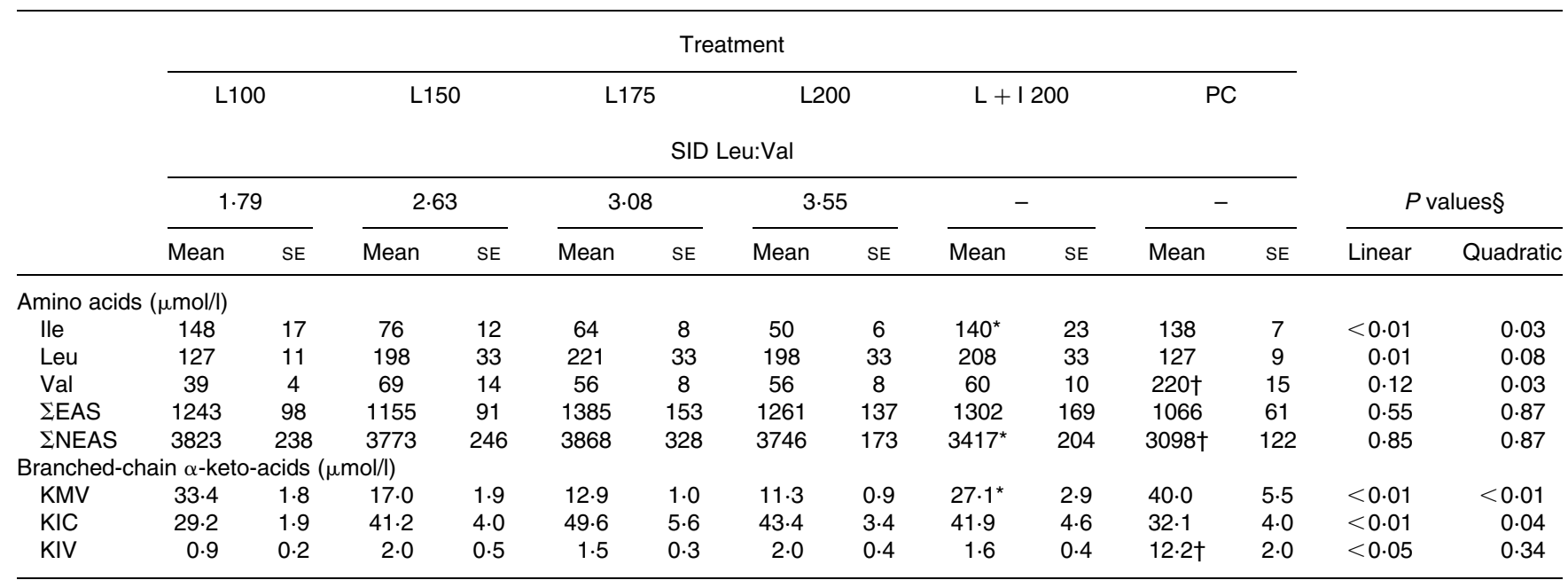

SID, standardised ileal digestible; $\Sigma$ EAS, sum of the essential amino acids; $\Sigma$ NEAS, sum of the non-essential amino acids; KMV, $\alpha$-keto- $\beta$-methylvalerate; KIC, $\alpha$-ketoisocaproate; KIV, $\alpha$-keto-isovalerate.

Mean values were significantly different from those of the L200 group: ${ }^{*} P<0.05$.

Mean values were significantly different from those of the $L 100$ group: $† P<0.05$.

†For details of animals and procedures, see Materials and methods.

$\S$ Polynomial orthogonal contrasts were estimated for L100 to L200. 

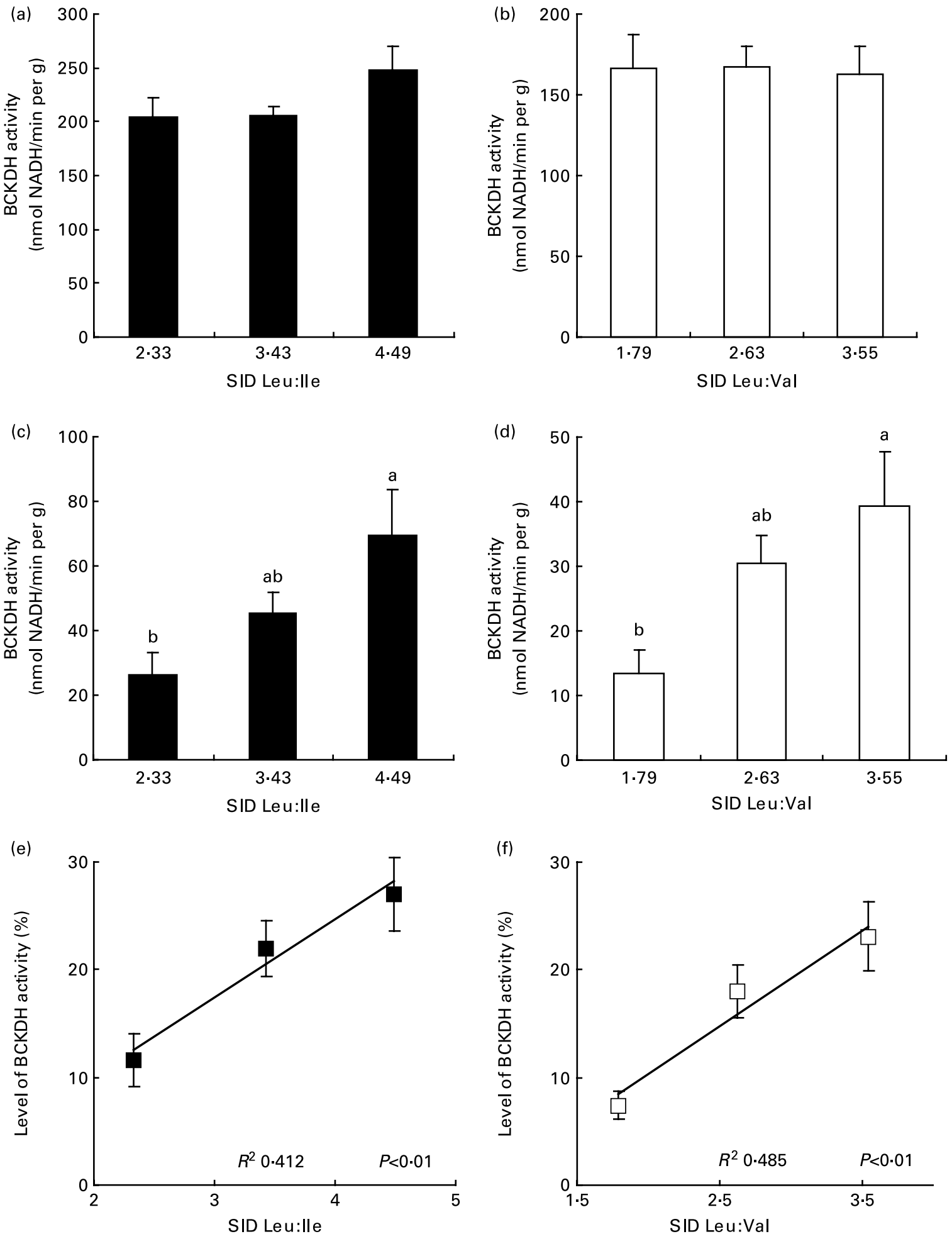

Fig. 1. Effects of increasing leucine supply on branched-chain $\alpha$-keto acid dehydrogenase (BCKDH). Total ((a) and (b)), basal ((c) and (d)) and relative ((e) and (f) BCKDH activities in the liver of pigs fed diets first limiting in isoleucine (expt 1) or valine (expt 2). For (e), $y=-7.5+8.9 x$ and for (f), $y=-4.2+7 \cdot 2 x$. Values are means with their standard errors depicted by vertical bars $(n 8) .{ }^{a, b}$ Mean values within a graph with unlike superscript letters were significantly different $(P<0.05)$. 
(Fig. 1(f)) increased linearly $(P<0 \cdot 01)$ in a dose-dependent manner as the Leu supply increased. Increasing the SID Leu:Val ratio from 1.79 to 3.55 increased the basal BCKDH activity and its level of activation approximately 3 -fold.

\section{mRNA expression}

The mean RNA integrity number value was 7.91 (SD 0.14), documenting an integer total RNA. For both expt 1 and expt 2, the internal control genes were unaffected by the experimental treatment $(P>0.05)$. In expt 1 , increasing the dietary Leu supply did not affect the expression of the mitochondrial BCAT (BCATm), BCKDH kinase (BCKDK) or BCKDH subunit $(\mathrm{E} 1 \alpha, \mathrm{E} 1 \beta$ and $\mathrm{E} 2)$ genes in skeletal muscle, heart, spleen, jejunum and ileum (data not shown). In liver tissue, however, the mRNA levels of genes for BCKDH E1 $\beta$ and BCKDK were significantly altered $(P<0.05$; Table 7$)$. Compared to L200, mRNA of the BCKDH E1 $\beta$ gene was significantly lower in L150 but unchanged in L100. In contrast, the mRNA levels of the BCKDK gene increased in L200.

Tissue-specific differences were observed in the mRNA expressions of the catabolic enzymes (Table 8), and are summarised as follows:

BCATm, heart $>>$ skeletal muscle, spleen, jejunum $>>$ ileum, liver;

BCKDH E1 $\alpha$, heart $>>$ liver $>>$ jejunum, skeletal muscle $>>$ spleen, ileum;

$\mathrm{BCKDH}$ E1 $\beta$, heart $>>$ liver $>>$ jejunum $>>$ skeletal muscle, spleen $>>$ ileum;

BCKDH E2, heart, liver $>>$ ileum, spleen, jejunum $>>$ skeletal muscle;

BCKDK, heart $>>$ skeletal muscle $>>$ liver $>$ jejunum $>$ ileum $>$ spleen.

In expt 2, no significant alterations were seen in mRNA expressions of the genes for BCATm, BCKDH subunits and BCKDK neither in muscle nor in liver tissue (data not shown). The mRNA expression of 4-hydroxyphenylpyruvate dioxygenase (4-HPPD) genes in liver and muscle tissue was neither influenced $(P>0.05)$ in expt 1 nor in expt 2 (data not shown). Increasing dietary Leu supply did not affect $(P>0.05)$ the mRNA expressions of the genes for growth hormone receptor (GHR), IGFBP, IGF acid labile subunit (IGFALS), IGF receptor and IGF-1 in skeletal muscle and liver tissue of expt 1, or in skeletal muscle of expt 2 (data not shown). However, in liver tissue, in expt 2, mRNA from the genes for GHR, IGFALS and IGF-1 was significantly decreased $(P<0 \cdot 05$; Table 9$)$.

\section{Discussion}

In the present work, the effects of increasing dietary Leu levels in isonitrogenous diets were determined. Surpluses of Ile (expt 1) or Val (expt 2) were avoided to get meaningful ratios to Leu and to increase the animals' sensitivity for interactions between the BCAA. In L100, the Ile supply was set at $5.0 \mathrm{~g} \mathrm{SID} \mathrm{Ile} / \mathrm{kg}$ diet (SID Leu:Ile ratio of 2.33). Incremental supplementation with Leu decreased the daily feed intake and gain in a dose-dependent manner. Increasing the SID Leu:Ile ratio from 2.33 to 4.49 (L100 to L200) decreased the daily feed intake and gain by 14 and $15 \%$, respectively.

In expt 2, the Val supply was set at $6 \cdot 2 \mathrm{~g} \mathrm{SID} \mathrm{Val} / \mathrm{kg}$ diet. Incremental Leu supplementation (SID Leu:Val ratio from 1.79 to 3.55 ; L100 to L200) decreased the daily feed intake, daily gain and feed efficiency linearly, in a dose-dependent manner, by 30,38 and $11 \%$, respectively. In the PC, the Val supply was increased to $7 \cdot 3 \mathrm{~g} \mathrm{SID} \mathrm{Val} / \mathrm{kg}$ diet, which increased the daily feed intake and gain, indicating suboptimal Val supply.

These findings are in accordance with the recent literature. Langer \& Fuller ${ }^{(22)}$ showed that excess dietary Leu decreases the nitrogen utilisation of pigs fed diets marginal for Ile or Val by $12-18 \%$. In earlier works, however, no effect occurred after increasing the Leu:Ile ratio from 1.7 to 3.0 in 15 $-51 \mathrm{~kg}$ pigs ${ }^{(8)}$, suggesting that increasing the Leu:Ile ratio above 3.5 may have negative effects in growing pigs ${ }^{(9)}$. In contrast, we showed that excess dietary Leu linearly decreased the performance, when a SID Leu:Ile ratio of 2.33 or a SID Leu: Val ratio of 1.79 was exceeded.

Table 7. Effects of increasing leucine supply on mRNA of branched-chain amino acid catabolism genes in the liver of weaned pigs fed diets first limiting in isoleucine (expt 1)* (Mean values with their standard errors)

\begin{tabular}{|c|c|c|c|c|c|c|}
\hline \multirow[b]{2}{*}{ Treatment } & \multirow[b]{2}{*}{ SID Leu:lle } & \multirow[b]{2}{*}{ BCATm } & \multicolumn{4}{|c|}{ BCKDH } \\
\hline & & & E2 & $\mathrm{E} 1 \alpha$ & $\mathrm{E} 1 \beta$ & BCKDK \\
\hline & $2 \cdot 33$ & & & & & \\
\hline \multirow[t]{3}{*}{ L100 } & Mean & 1.00 & 1.00 & 1.00 & $1.00^{\mathrm{ab}}$ & $1.00^{\mathrm{b}}$ \\
\hline & SE & 0.23 & 0.14 & 0.10 & 0.08 & 0.06 \\
\hline & 3.43 & & & & & \\
\hline \multirow[t]{3}{*}{ L150 } & Mean & 0.79 & 0.76 & 1.32 & $0.82^{b}$ & $1.05^{\mathrm{ab}}$ \\
\hline & SE & 0.15 & 0.17 & 0.13 & 0.04 & 0.04 \\
\hline & 4.49 & & & & & \\
\hline \multirow[t]{2}{*}{ L200 } & Mean & 1.02 & 0.940 & 1.35 & $1 \cdot 13^{\mathrm{a}}$ & $1.21^{\mathrm{a}}$ \\
\hline & SE & 0.37 & 0.11 & 0.20 & 0.07 & 0.07 \\
\hline
\end{tabular}

$\mathrm{BCKDH}$, branched-chain $\alpha$-keto acid dehydrogenase; SID, standardised ileal digestible; BCATm, mitochondrial branched-chain amino acid transferase; BCKDK, branched-chain $\alpha$-keto acid dehydrogenase kinase; 4-HPPD, 4-hydroxyphenylpyruvate dioxygenase.

${ }^{a, b}$ Mean values within a column with unlike superscript letters were significantly different $(P<0.05)$.

${ }^{*} 2^{-\Delta \Delta C_{\mathrm{t}}}$ values; for details, see Materials and methods. 
Table 8. Tissue-specific take-off values estimated by quantitative real time PCR for expt $1^{\text {* }}$ (Mean values with their standard errors)

\begin{tabular}{|c|c|c|c|c|c|c|c|c|c|c|c|c|}
\hline & \multicolumn{2}{|c|}{ LD muscle } & \multicolumn{2}{|c|}{ Heart } & \multicolumn{2}{|c|}{ Liver } & \multicolumn{2}{|c|}{ Spleen } & \multicolumn{2}{|c|}{ Jejunum } & \multicolumn{2}{|c|}{ Ileum } \\
\hline & Mean & $\mathrm{SE}$ & Mean & $\mathrm{SE}$ & Mean & $\mathrm{SE}$ & Mean & SE & Mean & SE & Mean & SE \\
\hline $\begin{array}{l}\text { BCATm } \\
\text { BCKDH }\end{array}$ & $24 \cdot 73^{c}$ & 0.16 & $22 \cdot 05^{d}$ & 0.11 & $29 \cdot 10^{a}$ & 0.18 & $25 \cdot 31^{\mathrm{bc}}$ & $0 \cdot 17$ & $25 \cdot 70^{b}$ & 0.17 & $28 \cdot 31^{a}$ & 0.36 \\
\hline $\mathrm{E} 1 \alpha$ & $19 \cdot 40^{\mathrm{b}}$ & 0.11 & $17 \cdot 19^{d}$ & 0.09 & $18.08^{c}$ & 0.08 & $20 \cdot 25^{\mathrm{a}}$ & 0.25 & $19 \cdot 28^{b}$ & 0.09 & $20 \cdot 57^{\mathrm{a}}$ & 0.19 \\
\hline E1 $\beta$ & $21 \cdot 17^{b}$ & 0.13 & $18 \cdot 66^{\mathrm{e}}$ & 0.05 & $19 \cdot 20^{d}$ & 0.06 & $21 \cdot 25^{\mathrm{b}}$ & 0.15 & $20 \cdot 52^{c}$ & 0.15 & $21 \cdot 84^{\mathrm{a}}$ & 0.11 \\
\hline E2 & $20 \cdot 91^{\mathrm{a}}$ & 0.13 & $18 \cdot 35^{\mathrm{c}}$ & 0.08 & $18 \cdot 37^{c}$ & 0.12 & $19 \cdot 59^{b}$ & 0.24 & $19 \cdot 61^{b}$ & 0.14 & $19 \cdot 55^{\mathrm{b}}$ & 0.17 \\
\hline BCKDK & $17 \cdot 43^{\mathrm{d}}$ & 0.09 & $15.45^{\mathrm{e}}$ & 0.06 & $18 \cdot 13^{c}$ & 0.05 & $19 \cdot 23^{\mathrm{a}}$ & 0.27 & $18 \cdot 28^{\mathrm{bc}}$ & $0 \cdot 10$ & $18 \cdot 76^{\mathrm{ab}}$ & 0.15 \\
\hline
\end{tabular}

LD, longissimus dorsi; BCATm, mitochondrial branched-chain amino acid transferase; BCKDH, branched-chain $\alpha$-keto acid dehydrogenase; BCKDK, branched-chain $\alpha$-keto acid dehydrogenase kinase.

a,b,c,d Mean values within a row with unlike superscript letters were significantly different $(P<0.05)$.

* For details of animals and procedures, see Materials and methods.

In $30-40 \mathrm{~kg}$ pigs fed Ile-limited diets, the negative effects of excess Leu on nitrogen utilisation are reversible by a simultaneous excess of $\mathrm{Val}^{(22)}$. In the present work, however, no benefits were detected for doubling the supply of Ile or Val in Leu-excessive diets. In contrast to Langer \& Fuller ${ }^{(22)}$, no significant increase in performance was observed, and the benefits of excess dietary Val in diets excessive in Leu could not be confirmed.

The basal dietary Ile and Val levels in expt 1 and 2 were chosen to be first limiting in order to guarantee that any observed negative effects of increasing dietary Leu levels would be direct and not obscured. Compared to PC, the marginality of the Ile supply in expt 1 was not reflected in the animals' performance, but was clearly demonstrated by a sharp decrease in plasma Ile and serum KMV levels. In expt 2, the marginality of the Val supply was indicated by a performance depression, and confirmed by a sharp decrease in plasma $\mathrm{Val}$ and serum KMV levels. The low plasma Ile and Val levels seen in the present work were in accordance with the literature ${ }^{(23-25)}$

In both trials, increasing the dietary Leu supply significantly increased the plasma Leu and serum KIC levels. Doubling the dietary Leu supply increased the plasma Leu and serum KIC levels by 64 and $45 \%$, respectively, in expt 1 , and by 59 and $49 \%$, respectively, in expt 2 . However, plasma Ile and
Val, and serum KMV and KIV levels decreased with increasing dietary Leu levels. These findings indicate increased BCAA catabolism in accordance with the literature. An increased catabolism of Val and Ile was seen in chicks fed diets with excess $\mathrm{Leu}^{(26)}$. In growing gilts fed diets containing high levels of dietary Leu for $7 \mathrm{~d}$, reduced plasma concentrations of Val, Ile and BCKA were seen ${ }^{(27)}$. The same effects were reported for rats ${ }^{(28,29)}$. The negative effects of excess dietary Leu are reversed by supplementation with Ile and Val in chicks, pigs and kittens ${ }^{(26,30,31)}$, confirming the hypothesis of an increased nutritional need for Ile and Val in diets with excess Leu.

The first step of the BCAA catabolism is a transamination catalysed by the BCAT, which exists as BCATm and cytosolic BCAT isoenzymes. The BCAT enzymes are widely distributed among tissues with cytosolic BCAT restricted to neural tissues. Therefore, we concentrated on BCATm. In the literature, the highest BCATm activities are reported for peripheral tissues such as skeletal muscle, whereas BCATm is not expressed in rodent and human liver ${ }^{(1,32)}$. To our knowledge, we are the first to publish an overview about tissue-specific BCATm RNA expression in pigs. In the present work, the highest BCATm RNA expression was seen in heart and skeletal muscle, whereas the lowest expression was seen in ileum and liver. Expression of BCATm RNA in the heart increased

Table 9. Effects of increasing dietary leucine supplementation on mRNA of genes related to growth hormone-insulin-like growth factor- 1 axis in the liver of pigs fed diets first limiting in valine (expt 2)*

(Mean values with their standard errors)

\begin{tabular}{|c|c|c|c|c|c|c|}
\hline Treatment & SID Leu:Val & GHR & IGFBP-3 & IGFALS & IGFR & IGF-1 \\
\hline & 1.79 & & & & & \\
\hline \multirow[t]{3}{*}{ L100 } & Mean & $1.00^{\mathrm{a}}$ & 1.00 & $1 \cdot 00^{\mathrm{a}}$ & 1.00 & $1.00^{\mathrm{a}}$ \\
\hline & SE & $0 \cdot 10$ & 0.14 & 0.17 & 0.13 & 0.09 \\
\hline & 2.63 & & & & & \\
\hline \multirow[t]{3}{*}{ L150 } & Mean & $0.62^{b}$ & 0.83 & $0.86^{\mathrm{ab}}$ & 1.04 & $0.53^{\mathrm{b}}$ \\
\hline & SE & 0.09 & 0.10 & 0.19 & 0.09 & 0.09 \\
\hline & 3.55 & & & & & \\
\hline \multirow[t]{2}{*}{ L200 } & Mean & $0.52^{b}$ & 0.85 & $0.58^{\mathrm{b}}$ & 1.03 & $0.29^{c}$ \\
\hline & $\mathrm{SE}$ & $0 \cdot 10$ & 0.13 & 0.08 & 0.09 & 0.07 \\
\hline
\end{tabular}

SID, standardised ileal digestible; GHR, growth hormone receptor; IGFBP-3, insulin-like growth factorbinding protein 3; IGFALS, insulin-like growth factor acid labile subunit; IGFR, insulin-like growth factor receptor; IGF-1, insulin-like growth factor-1.

${ }^{a, b, c}$ Mean values within a column with unlike superscript letters were significantly different $(P<0.05)$.

${ }^{*} 2^{-\Delta \Delta C_{t}}$ values; for details, see Materials and methods. 
about 137-fold compared to liver. These findings confirm the suggestion that the BCAA escape first-pass metabolism in the liver and thus are available to peripheral tissues. Increasing dietary Leu supply in the present work did not affect the mRNA levels of BCATm.

The second step in BCAA catabolism is catalysed by $\mathrm{BCKDH}$. The highest $\mathrm{BCKDH}$ activities are reported in liver with intermediate activity in heart, kidney and brain, and low activity in skeletal muscle ${ }^{(1)}$. This is largely consistent with the mRNA levels of weaned pigs, reported for the first time in this work. The highest mRNA levels of all analysed BCKDH subunit genes (E1 $\alpha, E 1 \beta$ and $E 2)$ were seen in heart and liver, and the lowest in skeletal muscle and ileum.

BCKDK activity is reciprocal to BCKDH activity. Therefore, decreased expression of the BCKDK gene could cause an enhanced BCKDH activity. However, a significant increase in BCKDK gene expression was seen in liver tissue at the highest Leu supply in expt 1 . Nonetheless, the alterations in BCKDK gene expression were minor changes of about $20 \%$, and only the bound form of the kinase regulates BCKDH activity. This should be considered in assessing the informative value of BCKDK mRNA expression with regard to changes in BCKDH activity. In the present study, tissuespecific expressions of BCKDK mRNA were reported for pigs, and found to be highest in heart and skeletal muscle, and lowest in spleen and ileum. The differences between skeletal muscle and liver tissue were $1 / 10$ of that seen in human subjects $^{(32)}$.

The KIC, the corresponding BCKA of Leu, plays an important role in the regulation of $\mathrm{BCKDH}$ activity. High KIC levels can increase the catabolism of the other BCAA by inhibition of the BCDKH kinase. This results in a less phosphorylated and therefore more active $\mathrm{BCKDH}$ complex $^{(33)}$. Block et al. ${ }^{(34)}$ reported that increases in plasma Leu paralleled changes in the activity of the BCKDH complex. In contrast to Leu, Val and Ile seem to be unimportant for the regulation of BCKDH activity. Infusions of Val or Ile failed to activate $\mathrm{BCKDH}$ in rats ${ }^{(35)}$. In the present work, doubling the dietary Leu supply increased the serum KIC levels by $45-49 \%$ and the basal activity of the liver BCKDH 2- to 3-fold. An increased rate of Leu oxidation was reported in rats when the dietary Leu supply exceeded the requirement for maximum rate of weight gain ${ }^{(28)}$. Increased BCKDH activity was seen in rats and pigs fed diets excessive in Leu ${ }^{(5,27,29)}$. The levels of BCKDH activity and its activity state in the present work were in accordance with the levels seen in growing gilts fed semipurified diets excessive in Leu, but marginal in Ile or $\mathrm{Val}^{(27)}$. The liver BCKDH activity states in the present work ranged from 7 to $27 \%$ and are comparable to that of human subjects $(26 \%)$, but much smaller than that of rats $(88 \%)^{(32)}$. The enhanced BCKDH activity in liver seen in this work resulted from an increased grade of activity. The total BCKDH activity as well as the gene expression of the $\mathrm{BCKDH}$ subunits $(\mathrm{E} 1 \alpha, \mathrm{E} 1 \beta$ and $\mathrm{E} 2)$ remained almost unaffected, indicating a posttranscriptional regulation.

Our findings are in accordance with Matsuzaki et al. ${ }^{(36)}$, who investigated the impact of increasing dietary Leu supply (up to $15 \%$ of the diet) on gene expression in rats using DNA microarrays. The data showed small alterations (less than 2-fold) in the expression of BCAA catabolism enzyme genes. However, it was reported that feeding
BCAA-enriched diets to rats increased the activity state of the BCKDH through a combination of decreased BCKDK activity and increased total BCKDH activity ${ }^{(5)}$. The increased $\mathrm{BCKDH}$ catabolism reported by Kuzuya et al. ${ }^{(5)}$ was mainly caused by an increased activity state. The total BCKDH activity increased maximally by $45 \%$, whereas the activity state increased 8.5 -fold. In conclusion, in pigs as in rats, excess dietary Leu seemed not to alter the gene expression of enzymes involved in BCAA catabolism to a great extent. Regulatory mechanisms that adapt to excess Leu appear to implicate mainly cellular posttranscriptional mechanisms.

In the context of dietary Leu oversupply, alternative pathways for Leu catabolism, which bypass BCKDH, might be of some importance. In addition to its oxidation by BCKDH, KIC can be converted to $\beta$-hydroxy- $\beta$-methylbutyrate by 4-HPPD (identical to KIC dioxygenase) ${ }^{(37)}$. The activity of 4-HPPD was found to be $14 \%$ of the total BCKDH activity in human liver ${ }^{(38)}$, illustrating its importance. In expt 1 and 2 , increasing dietary Leu supply had no impact on expression of the liver 4-HPPD gene. Feeding a BCAA-rich diet to rats increased BCKDH, but not 4-HPPD activity ${ }^{(38)}$. In conclusion, the effects of excess Leu on 4-HPPD require further investigation. 4-HPPD is an important enzyme of tyrosine catabolism ${ }^{(39)}$, and an impact of high KIC levels on tyrosine catabolism seems possible. However, we found no alterations in plasma tyrosine levels as the dietary Leu supply increased.

For several species, excess dietary Leu causes a growth depression $^{(1)}$. The present work confirms this general effect, although the mode of action remains unexplained. The hypothesis that growth retardation is a consequence of excess dietary Leu suggests a nutritional impact on the GH-IGF-1 axis, for which the literature contains some evidence ${ }^{(7)}$. Therefore, we decided to analyse the mRNA levels of GHR, IGF-binding protein 3, IGFALS, IGF receptor and IGF-1 in skeletal muscle and liver. In expt 1 , no impact on genes of the $\mathrm{GH}-$ IGF-1 axis in skeletal muscle or liver was observed when dietary Leu levels were increased. In contrast, increasing Leu supplementation decreased the mRNA levels of GHR, IGFALS and IGF-1 genes in liver tissue in expt 2. This is consistent with the greater extent of growth retardation in expt 2, compared to expt 1. Generally, fasting decreases the expression of the GH-IGF-1 axis genes ${ }^{(40,41)}$. In the present work, fasting or anorexia did not occur, but the daily feed intake decreased linearly with the increases in Leu supplementation. The stimulation of IGF-1 secretion by GH seems to be dependent on the availability of specific amino acids. Single deletions of arginine, proline, threonine, tryptophan or Val caused a block of GH-stimulated IGF-1 gene expression in cultured pig hepatocytes $^{(42)}$. However, the present work had no essential amino acid depletion. In contrast to previous works, we showed alterations in the expression of GH-IGF-1 axis genes caused by an increasing Leu supply in a sound organism. The increased Leu supply decreased the GHR, IGFALS and IGF-1 gene expression in expt 2 but not in expt 1, indicating a more extended Leu-induced nutrient shortage for expt 2 . We conclude that the greater growth retardation seen in expt 2 might be partially caused by decreased activity of the GHIGF-1 axis as a result of Leu-induced Val deficiency.

In the present work, feed intake decreased as the dietary Leu content increased. In force-fed chicks, it has been found that about $70 \%$ of performance depression caused by Leu 
oversupply was the result of a decreased feed intake ${ }^{(43)}$. It is known from preference trials that rats reject diets excessive in Leu and instead prefer an alternative diet even if it is protein free ${ }^{(44)}$. It has been shown by injection of L-Leu into the brain of rats that dietary Leu is indeed a nutrient signal, which can cause depressions of feed intake ${ }^{(45,46)}$. Leu activates the hypothalamic mammalian target of rapamycin pathway and decreases the adenosine monophosphate-activated protein kinase activity, which results in inhibition of neuropeptide $Y$ and stimulation of pro-opiomelanocortin expression ${ }^{(45,46)}$. Neuropeptide Y promotes feeding, decreases energy expenditure and silences pro-opiomelanocortin, whereas pro-opiomelanocortin promotes satiety ${ }^{(47)}$. Therefore, inhibition of neuropeptide $\mathrm{Y}$ and activation of pro-opiomelanocortin cause satiety and give an explanation for the Leu-induced anorexia. Inhibition of mammalian target of rapamycin with rapamycin inhibited the L-Leu-induced anorexia ${ }^{(45)}$.

In conclusion, growth depression as a consequence of excess dietary Leu is accompanied by decreased plasma levels of Ile and Val, and increased BCKDH activities, indicating an increase in BCAA catabolism. Regulation of BCAA catabolism mainly involved posttranscriptional mechanisms, because no major alterations were seen in gene expression of BCATm, BCKDH subunits or BCKDK. The alterations seen in the mRNA of GHR, IGFALS and IGF-1 in pigs fed Leu-excessive diets need further investigation.

\section{Acknowledgements}

Funding for the present project was provided by Arbeitskreis für Tierernährungsforschung Weihenstephan (ATW) e.V. Realisation of experimental and laboratorial work as well as writing was done by M. K. W. M. W. P. made mRNA expression analyses possible and provided laboratory facilities and assistance. Experimental design and conception, acquisition of financial resources and proof reading was done by F. X. R. There are no conflicts of interest.

\section{References}

1. Harper AE, Miller RH \& Block KP (1984) Branched-chain amino acid metabolism. Annu Rev Nutr 4, 409-454.

2. Yeaman SJ (1989) The 2-oxo acid dehydrogenase complexes: recent advances. Biochem J 257, 625-632.

3. Damuni Z, Merryfield ML, Humphreys JS, et al. (1984) Purification and properties of branched-chain alpha-keto acid dehydrogenase phosphatase from bovine kidney. Proc Natl Acad Sci U S A 81, 4335-4338.

4. Shimomoura Y, Nanaumi N, Suzuki M, et al. (1990) Purification and partial characterization of branched-chain alpha-ketoacid dehydrogenase kinase from rat liver and rat heart. Arch Biochem Biophys 283, 293-299.

5. Kuzuya T, Katano Y, Nakano I, et al. (2008) Regulation of branched-chain amino acid catabolism in rat models for spontaneous type 2 diabetes mellitus. Biochem Biophys Res Commun 373, 94-98.

6. Wieland $\mathrm{OH}$ (1983) The mammalian pyruvate dehydrogenase complex: structure and regulation. Rev Physiol Biochem Pharmacol 96, 123-170.

7. Sanderson IR \& Naik S (2000) Dietary regulation of intestinal gene expression. Annu Rev Nutr 20, 311-338.
8. Henry Y, Duée PH \& Rérat A (1976) Isoleucine requirement of the growing pig and leucine-isoleucine interrelationship. J Anim Sci 42, 357-364.

9. Taylor SJ, Cole DJA \& Lewis D (1984) Amino acid requirements of growing pigs. 5. The interaction between isoleucine and leucine. Anim Prod 38, 257-261.

10. Taylor SJ, Cole DJA \& Lewis D (1985) Amino acid requirements of growing pigs. 6. Isoleucine. Anim Prod 40, 153-160.

11. Chung TK \& Baker DH (1992) Ideal amino acid pattern for 10-kg pigs. J Anim Sci 70, 3102-3111.

12. Sauvant D, Perez JM \& Tran T (eds) (2004) Tables of Composition and Nutritional Value of Feed Materials. INRAAFZ-INAPG. Wageningen Academic Publishers, Wageningen, The Netherlands.

13. Stein HH, Sève B, Fuller MF, Moughan PJ \& de Lange CFM (2007) Invited review: amino acid bioavailability and digestibility in pig feed ingredients: terminology and application. J Anim Sci 85, 172-180.

14. National Research Council (1998) Nutrient Requirements of Swine, 10th rev ed. ed. Washington, DC: National Acadamic Press.

15. Naumann C \& Bassler R (1997) Die chemische Untersuchung von Futtermitteln. Methodenbuch, Band III. Melsungen: Verlag J. Neumann-Neudamm.

16. Commission directive 98/64/EC of 3 September 1998 establishing Community methods of analysis for the determination of amino-acids, crude oils and fats, and olaquindox in feedingstuffs and amending Directive 71/393/EEC (1998) Official Journal of the European Communities L 257, 14-28

17. AFNOR (1998) Determination of tryptophan. Association Française de Normalisation XPV 18-114, France

18. Pailla K, Blonde-Cynober F, Aussel C, et al. (2000) Branchedchain keto-acids and pyruvate in blood: measurement by HPLC with flourimetric detection and changes in older subjects. Clin Chem 46, 848-853.

19. Nakai N, Kobayashi R, Popov KM, et al. (2000) Determination of branched-chain $\alpha$-keto acid dehydrogenase activity state and branched-chain $\alpha$-keto acid dehydrogenase kinase activity and protein in mammalian tissues. Methods Enzymol 324, $48-62$.

20. Lowry SR (1992) Use and misuse of multiple comparisons in animal experiments. J Anim Sci 70, 1971-1977.

21. Livak KJ \& Schmittgen TD (2001) Analysis of relative gene expression data using real-time quantative PCR and the $2-\Delta \Delta$ CT method. Methods 25, 402-408.

22. Langer $S \&$ Fuller MF (2000) Interactions among the branchedchain amino acids and their effects on methionine utilization in growing pigs: effects on nitrogen retention and amino acid utilization. Br J Nutr 83, 43-48.

23. Bravo FO, Meade RJ, Stockland WL, et al. (1970) Reevaluation of the isoleucine requirement of the growing pig - plasma free isoleucine as a response criterion. J Anim Sci 31, 1137-1141.

24. Figueroa JL, Lewis AJ, Miller PS, et al. (2002) Nitrogen metabolism and growth performance of gilts fed standard corn-soybean meal diets or low-crude protein, amino acidsupplemented diets. J Anim Sci 80, 2911-2919.

25. Figueroa JL, Lewis AJ, Miller PS, et al. (2003) Growth, carcass traits, and plasma amino acid concentrations of gilts fed low-protein diets supplemented with amino acids including histidine, isoleucine and valine. J Anim Sci 81, 1529-1537.

26. Calvert CC, Klasing KC \& Austic RE (1982) Involvement of food intake and amino acid catabolism in the branched-chain amino acid antagonism in chicks. J Nutr 112, 627-635.

27. Langer S, Scislowski PWD, Brown DS, et al. (2000) Interactions among the branched-chain amino acids and their effects on methionine utilization in growing pigs: effects on plasma amino- and keto-acid concentrations and branched-chain keto-acid dehydrogenase activity. Br J Nutr 83, 49-58. 
28. Harper AE \& Benjamin E (1984) Relationship between intake and rate of oxidation of leucine and $\alpha$-ketoisocaproate in vivo in the rat. $J$ Nutr 114, 431-440.

29. Block KP \& Harper AE (1984) Valine metabolism in vivo: effects of high dietary levels of leucine and isoleucine. Metabolism 33, 559-566.

30. Fu SX, Fent RW, Allee GL, et al. (2006) Branched chain amino acid interactions increases isoleucine requirement in late-finishing pigs. J Anim Sci 84, Suppl 1, S283-S284.

31. Hargrove DM, Rogers QR, Calvert CC, et al. (1988) Effects of dietary excesses of the branched-chain amino acids on growth, food intake and plasma amino acid concentrations of kittens. J Nutr 118, 311-320.

32. Suryawan A, Hawes JW, Harris RA, et al. (1998) A molecular model of human branched-chain amino acid metabolism. Am J Clin Nutr 68, 72-81.

33. Paxton R \& Harris RA (1984) Regulation of branched-chain $\alpha$-ketoacid dehydrogenase kinase. Arch Biochem Biophys 231, $48-57$.

34. Block KP, Aftring RP, Mehard WB, et al. (1987) Modulation of rat skeletal muscle branched-chain $\alpha$-keto acid dehydrogenase in vivo: effects of dietary protein and meal consumption. J Clin Invest 79, 1349-1358.

35. Aftring RP, Block KP \& Buse MG (1986) Leucine and isoleucine activate skeletal muscle branched-chain $\alpha$-keto acid dehydrogenase in vivo. Am J Physiol 250, E599-E604.

36. Matsuzaki K, Kato H \& Sakai R (2005) Transcriptomics and metabolomics of dietary leucine excess. $J$ Nutr 135, 1571S-1575S.

37. Crouch NP, Lee MH, Iturriagagoitia-Bueno T, et al. (2000) Cloning, expression, and purification of mammalian 4-hydroxyphenylpyruvate dioxygenase/ $\alpha$-ketoisocaproate dioxygenase. Methods Enzymol 324, 342-343.

38. Xu M, Nakai N, Ishigure K, et al. (2000) The $\alpha$-ketoisocaproate catabolism in human and rat livers. Biochem Biophys Res Commun 276, 1080-1084.

39. Lindstedt S, Holme E, Lock EA, et al. (1992) Treatment of hereditary tyrosinaemia type 1 by inhibition of 4-hydroxyphenylpyuruvate dioxygenase. Lancet 340, 813-881.

40. Clemmons DR \& Underwood LE (1991) Nutritional regulation of IGF-1 and IGF binding proteins. Anпи Rev Nutr 11, 393-412.

41. Straus DS \& Takemoto CD (1990) Effect of fasting on insulinlike growth factor-1 (IGF-1) and growth hormone receptor mRNA levels and IGF-1 gene transcription in rat liver. Mol Endocrinol 4, 91-100.

42. Brameld JM, Gilmour RS \& Buttery PJ (1999) Glucose and amino acids interact with hormones to control expression of insulin-like growth factor-1 and growth hormone receptor mRNA in cultured pig hepatocytes. J Nutr 129, 1298-1306.

43. Calvert CC, Klasing KC \& Austic RE (1982) Involvement of food intake and amino acid catabolism of methionine in the rat. J Nutr 106, 1721-1736.

44. Rogers QR, Tannous RI \& Harper AE (1967) Effect of excess leucine on growth and food selection. J Nutr 91, 561-572.

45. Cota D, Proulx K, Blake Smith KA et al. (2006) Hypothalamic mTOR signalling regulates food intake. Science 312, 927-930.

46. Ropelle ER, Pauli JR, Fernandes MFA, et al. (2008) A central role for neuronal AMP-activated protein kinase (AMPK) and mammalian target of rapamycin (mTOR) in high-protein diet-induced weight loss. Diabetes 57, 594-605.

47. Gao Q \& Horvath TL (2007) Neurobiology of feeding and energy expenditure. Annu Rev Neurosci 30, 367-398. 